\title{
Responding to Multicultural Challenges: Camden Theological Library
}

\author{
by Gavin Glenn
}

$\mathrm{T}$

he Uniting Church in Australia has had a strong multicultural awareness from its beginnings. The Basis of Union states that the Uniting Church "believes that Christians in Australia are called to bear witness to a unity of faith and life in Christ which transcends cultural and economic, national and racial boundaries ..." The church has many culturally diverse congregations with worship regularly conducted in 40 different languages and diverse cultural styles. ${ }^{2}$ Worship services conducted at the chapel at the Centre for Ministry, where the library is located often include readings/songs/prayers in other languages. The new Moderator-elect of the NSW/ACT Synod is a Korean woman, Rev. Myung Hwa Park.

The library currently has around 450 members

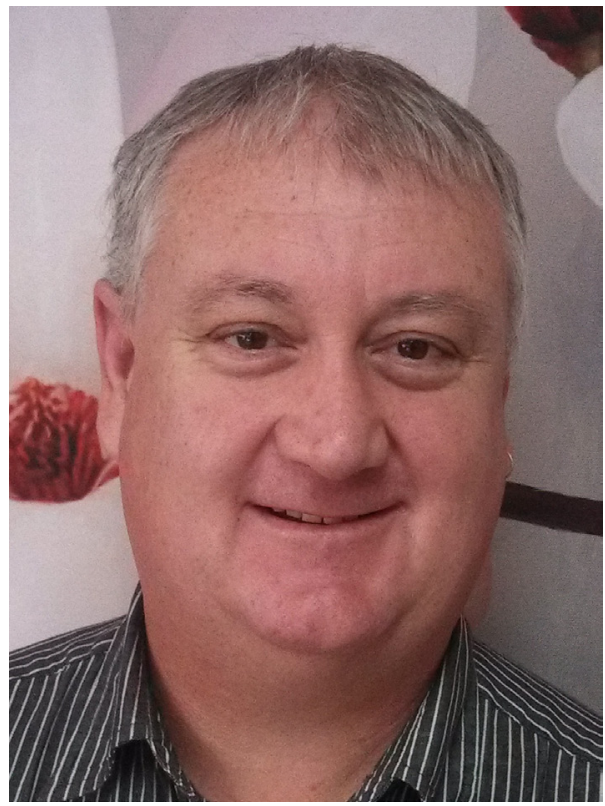
from a diverse range of backgrounds. Through an online survey conducted last year among students of the United Theological College (UTC) who are library members it was identified that almost $50 \%$ of our users come from backgrounds other than Australia with the most significant numbers coming from Korea and various Pacific Islands. Other backgrounds include Lebanon, China, Africa, Indonesia and the USA. These varying backgrounds can lead to challenges for the library staff and users. UTC, together with Charles Sturt University (CSU), provide subjects for Hannam University theology degrees however the majority of Korean students are studying through UTC in English.

The library has a significant number of books in Korean (currently 2,200 individual titles) and a small collection of books in Indonesian. The Korean collection is funded by CSU while the Indonesian collection was based on donations from an Australian/Indonesian congregation. While the library is interested in adding other language collections there is

1 Basis of Union, paragraph 2.

2 Uniting Church in Australia. Synod of NSW and the ACT. What is the Uniting Church? . 2002. http://nsw .uca.org.au/schoolprojects/whatistheuca.htm (accessed June 11, 2013). 


\section{"For those Korean}

patrons in the

library that are more

comfortable using

the Korean language

we provide Korean

keyboards to assist

them with using the

library computers.

All computers within

the library are

enabled for Korean

characters." limited funding available for this and in many cases limited material available. This is especially apparent in regard to Pacific Island languages with cultures largely built on oral tradition rather than written. In order to build collections for other languages there is also a need for a level of support from patrons of those backgrounds which, to date, has not been forthcoming.

Bi-lingual catalogue records for other language material include titles and authors in that language and can be searched for in those languages. This includes searching in Korean characters. Korean records are created by our part time Korean cataloguer. For other languages we utilise volunteers from existing library users. The catalogue is capable of displaying and accepting a range of different language characters including Arabic and Chinese. While we don't currently have resources in these languages we recognise the possibility of needing to provide them in the future.

We also provide access, through our discovery layer catalogue "Revelation", to Korean language theological journal databases. Again these are searchable using both English and Korean characters.

We have Bibles in a wide range of languages relevant to our patrons.

For those Korean patrons in the library that are more comfortable using the Korean language we provide Korean keyboards to assist them with using the library computers. All computers within the library are enabled for Korean characters.

There are a range of challenges in dealing with people from different cultural backgrounds. Some have very limited English skills. This is often the case with many of our Korean patrons who are able to conduct much of their study in their own language. As one of our part time employees is Korean, she is often able to assist with communication where necessary.

For many of our users with English as a second language, communicating their questions and concerns can be difficult and some are reluctant to seek assistance because of this and means that staff need to be alert to any signs of unease with patrons and be ready to offer assistance where needed.

It is also important, where speaking with someone who does not have strong English skills, to speak clearly and avoid using jargon and slang.

We also have two Islamic women currently undertaking postgraduate research. To support them we provide space for them to pray when needed. There is also a need to be aware of their potential discomfort in dealing with male staff.

To support those people who have limited familiarity with libraries and/or computers (this is particularly evident with many of those from the Pacific Islands), the library has employed a Library Confidence Facilitator whose role is to provide one on one coaching and support in using the library and catalogue. UTC also employs a first year mentor (a former Library staff member with a Pacific Island 


\section{"Our display for}

Kiribati, in addition

to highlighting

the culture,

also provided

\section{information}

regarding the

challenges being

faced by the people

there from climate

change." background) who also provides support to students. The college also provides a Study Skills Tutor who is able to assist people attain the skills needed for their studies.

Over recent years the library has hosted displays of various cultures represented by library patrons. These are usually held around a national day for the culture represented. These displays are co-ordinated by library staff but rely on the loan of display material from interested library members. They have proved very popular with many people keen to exhibit their cultural heritage. When we suggested a display to represent Korea one student provided (among other material) his wife's wedding dress which had been made by her future mother-inlaw. Unfortunately when he brought it in he had no idea how it went together and quickly called his wife to come in and show us how to hang it. Our display for Kiribati, in addition to highlighting the culture, also provided information regarding the challenges being faced by the people there from climate change. Some really get into the spirit of the display. For our Nuiean display two students, in addition to providing material for the display offered to give a brief talk. People were invited to come into the library during their lunch break and were welcomed by a traditional Nuiean warriors chant followed by a fascinating history of the introduction to Christianity to the island and some information about the people's participation in World War 1 which was a tremendous culture shock to the men who volunteered. Following this we were treated to a Nuiean hymn sung by the two students and their family. Our current display links into NAIDOC week commemorating 50 years since the Yirrkala Bark Petitions. Our display includes a wide variety of material relating to Indigenous art, history, culture and social issues. 